ANÁLISE REGIONAL DAS MESORREGIOES DO ESTADO DO PARANÁ NO FINAL DO SÉCULO XX

JANDIR FERRERA DE LIMA, LUCIR REINALDO ALVES, MOACIR Piffer e Carlos Alberto Piacenti

CUSTO NA DÍVIDA PÚBLICA INTERNA DA REDUÇĀO DA VULNERABILIDADE EXTERNA BRASILEIRA ATRAVESS DO AUMENTO DAS RESERVAS INTERNACIONAIS

ROBERTO MEURER

DETERMINAČÃO DE UM MODELO DE PREVISÃO UNIVARIADO PARA PREÇOS DE LEITE PAGOS AOS PRODUTORES EM SANTA CATARINA

ARLei LUiz Fachinello e Mirian Rumenos Piedade Bacch!

VIABILIDADE DE ESTRATÉGIAS DE HEDCE COM CONTRATOS FUTUROS DE BOI GORDO NO BRASIL DIANA de MEDEIROS BAPTISTA E DANILO ROLIM DIAS DE AGUIAR

ATAQUES ESPECULATIVOS E CRISES CAMBIAIS NA ARGENTINA E NO BRASIL: UMA ANÁLISE COMPARATIVA KELLEN FrAGa DA SIIVA E FERnANDO FERRARI FILHO

A TEORIA DOS FUNDOS DE EMPRÉSTIMOS: UM ESTUDO DOS MODELOS AGREGADOS NEOCLÁSSICO E KEYNESIANO

ALAIN HERSCOVICI

CRIME ECONÔMICO NO PARANÁ: UM ESTUDO DE CASO SALETE POLONIA BoriLLI E PERY Francisco AsSIS SHIKIDA

APLICAÇĀO DA NOVA ECONOMIA INSTITUCIONAL AO AMBIENTE PORTUÁRIO: ANÁLISE DOS CUSTOS DE TRANSAÇĀO NO PORTO DE SANTOS

CinTIA RETZ LUCCI, ALCINDO FERNANDES GONÇALVES E

ROBERTO FAVA SCARE

REDUÇÃO DE MANDATOS LEGISLATIVOS: O DEBATE ADORMECIDO

Francisco josé de Queiroz PINHeiro, Charles lima de ALMEIDA E TITO BELCHIOR SILVA MOREIRA

ANÁLISE ECONÔMICA E AMBIENTAL DE SISTEMAS DE TERMINACCÃO DE SUINNOS COM A APLICACCÃO DOS CONUUNTOS FUZZY

JULIO EDUARDo ROHENKOHL, ORLANDO MARTINELLI E MARCOS ALVES DOS REYS

RESENHA: THE GLOBAL EVOLUTION OF INDUSTRIAL RELATIONS EVENTS, IDEAS AND THE IIRA

CARLOS HENRIQUE HoRN
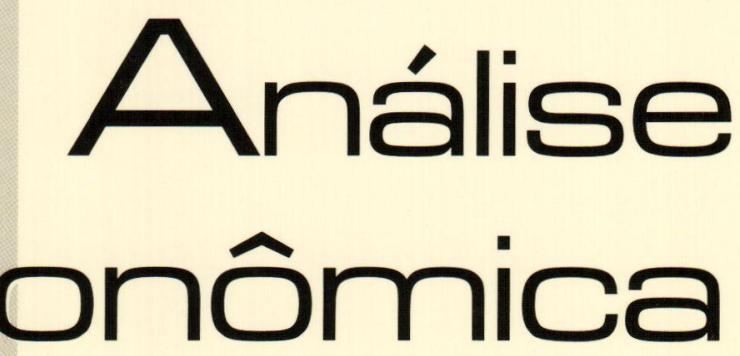


\section{A Revista Análise Econômica agradece a colaboração dos pareceristas dos números 45 e 46 , abaixo relacionados}

Abraham Benzaquen Sicsu

Adelar Fochezalto

Ademar Ribeiro Romeiro

Ademir Clemente

Alexandre Stamford da Silva

Ana Lucia Kassouf

Andre Luis Rossi de Oliveira

Andre Tosi Furtado

Andrea Sales Soares de Azevedo Melo

Angela Antonia Kageyama

Antonio Wilson Ferreira Menezes

Armando João Dalla Costa

Bernardo Mueller

Carlos Frederico Leao Rocha

Claudio Roberto Fóffano Vasconcelos

Cláudio Diissey Shikida

Clesio Lourenco Xavier

Dullio de Avila Berni

Eliezer Martins Diniz

Emerson Fernandes Marçal

Eugenio Lagemann

Fernando Ferrari Fitho

Francisco Casimiro Filho

Franklin Leon Peres Serrano

Frederico Gonzaga Jayme Jr.

Geraldo Edmundo Silva Jr.

Helder Ferreira de Mendonça
Helder Queiroz Pinto Junior Izabel Cristina Takitane

Joaquim José Martins Guilhoto

Joilson Dias

Jose Gabriel Porcile Meirelles

José Rubens Damas Garlipp

Julio César de Oliveira

Lovois de Andrade Miguel

Marcelo Savino Portugal

Marcio Holland de Brito

Marco Aurelio Crocco Afonso

Marcos Costa Holanda

Mônica Viegas Andrade

Paulo Dabdab Waquil

Paulo Sergio Fracalanza

Pedro Bandeira

Pedro Valentim Marques

Pery Francisco Assis Shikida

Renato Leite Marcondes

Roberto Camps Moraes

Ronald Otto Hilbrech

Ronaldo de Albuquerque e Arraes

Ronaldo Seroa da Motta

Thompson Almeida Andrade

Tito Belchior Silva Moreira

Valmor Marchetti

Vladimir Kuhl Teles 


\title{
Redução de mandatos legislativos: o debate adormecido
}

\author{
Francisco José de Queiroz Pinheiro* \\ Charles Lima de Almeida** \\ Tito Belchior Silva Moreira***
}

Resumo: Este artigo analisa a duração dos atuais mandatos legislativos no Brasil e as conseqüências políticas resultantes da escolha destes parâmetros. Primeiramente, nós simulamos um modelo muito simples de seleção por competência para mostrar que os resultados explicam os longos mandatos adotados pelos países desenvolvidos parlamentaristas de Europa. Com base nos resultados da simulação, nós também sugerimos a taxa de reeleição como um indicador da maturidade eleitoral. Nós encontramos que nem a renda per capta, nem o fator ideológico explicam as diferenças nas taxas de reeleição nos estados do Brasil, mas o viés na representação dos estados explicam tais diferenças. Neste contexto, nós argumentamos que uma redução da duração do mandato legislativo no Brasil induziria a uma maior estabilidade política e a uma maior competitividade eleitoral.

Palavras-chave: termo legislativo, estabilidade política e competitividade eleitoral

\begin{abstract}
This paper aims to put in evidence the current term lengths of legislative offices in Brazil and the political outcomes that results from the choice of these parameters. First, we simulate a very simple model of competence selection to show that the results explain the long terms adopted by the developed parliamentarist countries of Europe. Based on the simulation's results, we also suggest the reelection rate as an indicator of electoral maturity. We found that the income per capita doesn't explain the differences in the reelection rates in states of Brazil, neither does the ideological factor, but the bias in representation does explain those differences. In this context, we argue that a reduction of legislative's term lengths in Brazil would induce more political stability and electoral competitivity.
\end{abstract}

Keywords: legislative's term, political stability and electoral competitivity

JEL Classification: D72, D80, K19.

* Tribunal de Contas da União: franciscojq@atcu.gov.br

** Tribunal de Contas da Uniāo: charlesla@tcu.gov.br

***Universidade Católica de Brasilia: tito@pos.ucb.br

Recebido em janeiro de 2006. Aceito em junho de 2006.

Pinheiro, F. J. Q. ; Almeida, C L. ; Moreira, T. B. C. Redução de mandatos legislativos... 


\section{Introdução}

Há um debate em pleno curso nos Estados Unidos sobre a imposição de controles na atividade dos políticos daquele país. E para que se tenha noção da importância desse fenômeno, convém registrar que trata-se de "uma das mais fortes mensagens anti-Washington enviada pelo público ao Congresso nas últimas décadas". ${ }^{1}$

As conseqüências desse debate, travado já há algum tempo, são expressivas. Até 1998, dezoito estados americanos adotaram leis limitando o número de mandatos que seus parlamentares estaduais poderiam cumprir, fazendo com que, já em 1996, 56 parlamentares fossem atingidos pela medida. No Brasil, são notórios os sinais de desconfiança e desaprovação popular em relação às instituições parlamentares dos três níveis de governo, mas a insatisfação praticamente não tem resultado na discussão e aprovação de medidas concretas que tragam maior controle social sobre o desempenho dos parlamentares.

Ao tratar dos vereadores, deputados estaduais, distritais, federais e dos senadores, a Constituição Federal fixa-lhes a duração dos mandatos em quatro anos para os primeiros e oito anos para o último. Essa definição da duração dos mandatos vem desde a promulgação da primeira constituição republicana e foi mantida na Carta em vigor justamente por essa tradição. ${ }^{2}$

Em face da intocabilidade dos dispositivos constitucionais que tratam da duração dos mandatos parlamentares, representado pelo debate praticamente inexistente acerca desse tema, a despeito de sua relevância para o funcionamento do sistema político, em sensível contraste com a experiência norte-americana, o objetivo principal desse artigo é contribuir para o florescimento de uma literatura acadêmica específica para a análise das conseqüências de alterações nas durações dos mandatos, e a partir daí fixar a noção, junto à sociedade, de que as durações de mandatos não passam de parâmetros institucionais plenamente suscetiveis de escolha social.

A abordagem deste artigo é a da teoria da informação e da moderna teoria positiva da regulação, da qual uma revisão praticamente completa é encontrada em Laffont e Tirole (1993). Essa abordagem considera a assimetria de informação entre os eleitores,

1 The Washington Post, edição de 26/10/1992

2 A Seção 4 deste artigo reporta-se às discussōes travadas na Assembléia Nacional Constituinte de 1987-1988. 
os potenciais candidatos a cargos legislativos e os políticos em efetivo exercício do mandato. Este artigo assume que parte substancial do controle eleitoral resulta do relacionamento entre os eleitores e o último grupo citado, os políticos no poder. O controle é feito predominantemente por meio da seleção por competência, pelo qual, os políticos mais competentes continuam no poder, independentemente do grau de conhecimento que os eleitores têm dos políticos potenciais.

O artigo está estruturado como segue. A seção 1 relata a experiência internacional sobre a duração de mandatos parlamentares, em que se adianta a discussão teórica para tentar explicar porque em países desenvolvidos da Europa, de sistema parlamentarista de governo, adotam-se mandatos legislativos com durações semelhantes às do Brasil. A seção 2 trata da experiência brasileira, compreendendo uma discussão da forma como foram aprovados os dispositivos constitucionais que tratam da duração. A seção 3 é dedicada aos desenvolvimentos teóricos relacionados com a duração dos mandatos e seus efeitos sobre o funcionamento do sistema político. A seção 4 aborda a perda de um importante mecanismo de controle eleitoral, causada pela duração igual e coincidente de mandatos executivos e legislativos, no Brasil. A seção 5 colige os pontos relevantes abordados em seções anteriores para discutir as razões de um debate tão escasso sobre a duração de mandatos legislativos no Brasil. A seção 6 conclui.

\section{A experiência internacional}

A publicação anual Almanaque Abril da Editora Abril considera relevante, ao resumir os dados econômicos, políticos e sociais de cada país do mundo, incluir entre os dados políticos os referentes à duração dos mandatos legislativos e executivos. Implícita nesse fato, poderia estar a noção de que essa informação pode dar uma idéia do grau de desenvolvimento político do país considerado. Da edição em CD-rom de 1998, pode-se destacar os seguintes pontos relativos a alguns países selecionados:

Vê-se que o sistema presidencialista de governo é eminentemente americano. O continente seguiu o modelo adotado na constituição da primeira nação a conseguir sua independência política da metrópole européia. Depois, os Estados Unidos passaram a incentivar e apoiar a independência das demais colônias americanas, o que pode explicar a disseminação do seu modelo consțitucional. Assim, a adoção desse modelo - república, federalismo, presidencialismo - foi acontecendo à medida que os países iam se tornando independentes. O Brasil, que, à 
época de sua independência gozava do status de Reino Unido ao de Portugal, talvez tenha sido a exceção mais notável, já que se tornou uma monarquia constitucional nos primeiros tempos como nação livre, só vindo a adotar o modelo constitucional dos Estados Unidos quando proclamou a república.

Poucos países do continente, no entanto, copiaram a duração de dois anos para os mandatos legislativos (representantes do povo) que foi inscrita na constituição americana desde a sua criação, isso por razões históricas que não cabem, no objetivo deste trabalho, discutir.

O sistema parlamentarista de governo, sob república ou monarquia, predomina na Europa e na Ásia. Nos países que adotaram esse sistema, não se nota grande variação no tamanho dos mandatos legislativos, sejam eles desenvolvidos ou em desenvolvimento.

O modelo a seguir procura explicar a existência de países desenvolvidos, notadamente da Europa, com longa duração dos seus mandatos legislativos. A possível explicação é a de que a longa tradição democrática vivida por esses países faz com que os beneficios de uma redução de mandatos não sejam tão explícitos.

Os resultados do modelo são derivados de simulações computacionais, que vêm tendo amplo uso em estudos políticos. ${ }^{3}$ Sua estrutura é bastante simplificada, baseando-se unicamente na decisão do eleitorado, que, por sua vez, baseia-se unicamente no desempenho dos políticos no poder. A cada eleição, o eleitorado reelege apenas os parlamentares que tenham tido desempenho igual ou superior a um valor mínimo fixado com base em um indicador unidimensional e, substituindo os que tiveram desempenho inferior a esse valor. $O$ desempenho potencial dos políticos disponíveis distribui-se normalmente, com média zero $\left(\mu_{e}=0\right)$ e variância variável $\left(\sigma^{2}\right)$ de acordo com as simulaçóes a seguir. O ponto de corte que o eleitorado leva em conta na sua decisão, $v$, é dado por:

$$
v=\mu_{p}-\alpha \cdot \sigma_{p}
$$

onde $\mu$ p é a média do desempenho dos políticos com mandato, $\alpha$ é uma variável que captura o grau de rigor com que o desempenho parlamentar é avaliado e op é o desvio-padrão do desempenho dos políticos.

O eleitorado observa perfeitamente o desempenho e de cada parlamentar, mas não conhece, a priori, o desempenho potencial do

3 Adams (1997) relata esse processo. Nesse estudo, as simulações realizadas se valem de características multidimensionais dos políticos. 
candidato. Adotando-se valores distintos para a e para o desvio-padrão do desempenho potencial dos candidatos se, foram feitas simulações de eleições com essa estrutura. Em cada eleição, calculou-se a média de $e$.

Os principais resultados das simulações realizadas indicam que:

a) há tendência à convergência, principalmente se o grau de exigência de desempenho mínimo não for tão elevado, o "ótimo" se situando-se próximo à média do desempenho parlamentar $(\alpha=0)$;

b) a taxa de reeleição cresceu em todas as simulações, chegando a praticamente $100 \%$ quando há pouca exigência de desempenho $(\alpha=1)$; quando o nível de exigência situa-se próximo à média do desempenho parlamentar $(\alpha=0)$, a taxa de reeleição evolui de $57,5 \%$ (que é uma taxa próxima à brasileira) para cerca de $70 \% \mathrm{e}$

c) o processo leva a maiores níveis de desempenho parlamentar quando a variância da população de onde saem os eleitos é maior.

O segundo fato é amplamente verificado nas democracias desenvolvidas e, aliás, é visto como um problema, já que ele se manifesta, na realidade, como um baixo grau de competição eleitoral durante os pleitos. Estudos reportados por Daniel e Lott (1997) indicam que a maior taxa de rotatividade nos Estados Unidos nos últimos 44 anos foi de apenas cerca de $24 \%$, o que significa taxa de continuação ou reeleição de $76 \%$. Wrighton e Squire (1997) trazem uma boa literatura tratando desse problema Em seu estudo, esses autores utilizam como indicador o número de distritos em que só comparece um único candidato (o incumbente) em eleição para a Casa de Representantes do povo. Esse número vem caindo ao longo do tempo, mas em 1992 ainda foi de 40. É até algo inconcebível no Brasil de hoje, caso houvesse eleição distrital para a Câmara, que surgisse um único distrito em todo o País com candidatura única.

O modelo utilizado, apesar de suas limitações, ${ }^{4}$ sugere uma explicação teórica para a existência de mandatos legislativos com longa duração em países desenvolvidos com sistema parlamentarista de governo, que é a de que, a par do uso desse sistema, a tradição democrática já levou esses países a etapas de alto grau de desempenho parlamentar e de satisfação eleitoral, não se esperando ganhos substanciais com a redução dos mandatos.

4 A hipótese de que o eleitorado observa perfeitamente o desempenho dos parlamentares pode ser bastante restritiva se o grau de informação dos eleitores é pequeno; o modelo não leva em conta, também, as barreiras à entrada erguidas pelos incumbentes (v. seção 3.3), que podem variar com a duração do mandato. 


\section{A experiência brasileira}

No Brasil, nas duas últimas eleições para a Câmara dos Deputados (1994 e 1998), a taxa global de reeleição para o país passou de 46\% em 1994 para 49\% em 1998.

Procurou-se formular um modelo econométrico para testar as possíveis causas das diferenças existentes entre as taxas de reeleição dos diversos estados brasileiros. Pensou-se na renda per capita dos diversos estados, em um fator ideológico a ser adiante explicado e na relação entre o tamanho da bancada do estado e na sua população. Esta última variável procura controlar para o possível viés introduzido pela regra fixada no artigo $45, \S 1^{\circ}$ da Constituição Federal, que prevê o mínimo de oito deputados e o máximo de setenta para as bancadas estaduais. $^{5}$

Chegou-se, assim, ao seguinte modelo econométrico geral, com todas as variáveis em logaritmos, uma vez que assumiu-se a proporcionalidade direta:

$T X R E=\beta_{0}+\beta_{1} Y+\beta_{2} I D E O L+\beta_{3} T B A N C$, onde:

TXRE é o logaritmo da taxa de reeleição; $Y$ é o logaritmo da renda per capita do estado; IDEOL é o logaritmo de um fator representativo do peso ideológico da bancada e TBANC é o logaritmo da relação entre o número de cadeiras da bancada e a população do estado representado.

O fator ideológico é a relação entre o número de deputados pertencentes a partidos reconhecidos ou declarados como de esquerda (PT, PDT, PCdoB, PPS, PSB) e o número total de cadeiras da bancada.

As estimativas dos parâmetros estão resumidas nas Tabelas 1 e 2 a seguir.

Tabela 1

\begin{tabular}{|c|c|c|c|c|}
\hline \multicolumn{5}{|c|}{$\begin{array}{l}\text { Mínimos Quadrados (Eviews 4.0) - Variável dependente é TXRE } \\
\text { Número de observações: } 54\end{array}$} \\
\hline Variável & Coeficiente & Erro Padrão & Estatística t & Signif. \\
\hline$\beta_{0}$ & $-2,791619$ & 1,199676 & $-2,326977$ & 0.0241 \\
\hline$\beta_{l}$ & $-0,068488$ & 0,106760 & 0,641514 & 0,5241 \\
\hline$\beta_{2}$ & $6.66 \mathrm{E}-05$ & 0,000122 & 0,545499 & 0,5878 \\
\hline$\beta_{3}$ & 0,212738 & 0,082027 & $-2,593517$ & 0,0124 \\
\hline
\end{tabular}

5 Essa regra consiste em uma espécie de divisão proporcional "restrita": trata-se de dividir um número fixo de cadeiras, 513, proporcionalmente à população de cada Estado (conforme Lei Complementar $n^{\circ} 78 / 1993$ ), contanto que a menor bancada não seja inferior a oito, e a maior não seja superior a setenta. Com isso, o critério de um voto por eleitor não pode ser atendido. 
Tabela 2

\begin{tabular}{|c|c|c|c|c|}
\hline $\begin{array}{l}\text { Mínimos Quad } \\
\text { Numero de obs }\end{array}$ & $\begin{array}{l}\text { ews } 40 \text { ) - V } \\
54\end{array}$ & lependente é & & \\
\hline Variável & Coeficiente & Erro Padrão & Estatistica $t$ & Signif. \\
\hline$\beta_{0}$ & $-3,363352$ & 0,885754 & $-3,797164$ & 0.0004 \\
\hline$\beta_{3}$ & $-0,211798$ & 0,074746 & $-2,833590$ & 0,0065 \\
\hline
\end{tabular}

Se tomarmos a taxa de reeleição como uma medida da maturidade eleitoral, uma interpretação possivel desses resultados é que a renda per capita é pouco significativa para explicar as diferenças nas taxas de reeleição, indicando que, sob esse aspecto, as decisões do eleitorado se desenrolam da mesma maneira em todo o território nacional. Tem-se assim uma cultura política uniforme em todo o país. Do mesmo modo, o peso ideológico contribui pouco para as diferenças nas taxas de reeleição, indicando que a volatilidade na representação política é igual em todos os extratos ideológicos.

Já a variável indutora de maior competitividade, via restrição de aumento de bancada, mostrou-se significativa como explanatória das diferenças entre as taxas de reeleição em todas as regressōes, embora o valor de $\mathrm{R} 2$ indique a existência de outras variáveis explicativas, não abordadas neste estudo. O sinal negativo da constante na segunda regressão (Tabela 2) se explica pelo fato de se tomarem os logaritmos dos dados. O sinal negativo do coeficiente da variável é coerente com a interpretação de que os parlamentares dos estados atingidos pela restrição de bancada estão aumentando o seu desempenho parlamentar, dada a maior competitividade eleitoral a que estão sujeitos.

O que esses exercícios revelam é que o sistema político-eleitoral brasileiro pode ter um padrão que não é muito diferente do verificado em outros países do mundo. Os eleitores procuram desempenho de seus representantes políticos, e estes sentem necessidade de fazer ver aos eleitores o resultado de suas ações, para que possam permanecer no poder. Esse processo leva logicamente à melhoria do desempenho parlamentar, como tem sido observado na experiência democrática reiniciada recentemente. ${ }^{6}$

O processo funciona de acordo com os parâmetro externos a que está submetido, e a duração de mandatos, ou a freqüência com que são realizadas eleições, é um deles. Sua influência sobre os resultados gerais será analisada nos tópicos seguintes. Interessa, nesse

- Das CPIs do Congresso, já resultaram um inpeachment presidencial e a cassação de vários parlamentares acusados de corrupçāo. Os trabalhos das comissões ordinárias tendem a ser revitalizados e valorizados (conf. Pereira and Muller, 2004).

Pinheiro, F. J. Q. ; Almeida, C. L. ; Moreira, T. B. C. Redução de mandatos legislativos... 
momento, fazer um breve retrospecto sobre como a questão foi tratada na Assembléia Nacional Constituinte que elaborou a Constituição atualmente em vigor.

Da análise das atas das reuniōes da Subcomissão do Poder Legislativo da Assembléia Nacional Constituinte, resultou que as discussões sobre a duração de mandatos foram praticamente inexistentes. A pauta foi dominada pelos temas do sistema de governo e da instituição do voto distrital, que ainda hoje, quando a reforma política volta a ocupar a agenda nacional, dividem os políticos e cientistas políticos (entre presidencialistas e parlamentaristas, no primeiro caso, e proporcionalistas e distritalistas, no segundo). ${ }^{\text {? }}$

Mas a subcomissão, como ocorre com as comissões parlamentares do Brasil, ${ }^{8}$ estava sujeita a sérias limitações no seu poder de encaminhar as decisões que seriam tomadas na área de que se ocupava. Isso porque a qualquer constituinte era permitido apresentar emendas sobre os assuntos que desejasse, cabendo à Comissão de Sistematização elaborar o texto básico resultante da análise das emendas dos constituintes. A opinião da Subcomissão era, assim, apenas mais uma dentre muitas, e o efetivo poder de encaminhamento residia na Comissão de Sistematização. Desse modo, pode-se ir direto à Sessão da Assembléia que aprovou, em primeiro turno, o texto básico sobre a organização do Poder Legislativo e as emendas a esse texto discutidas na oportunidade.

A única emenda tratando da duração de mandatos foi apresentada pelo Constituinte Maguito Vilela, que, sintomaticamente, não pertencia à Subcomissão do Poder Legislativo. A emenda propunha a redução do mandato de senador de oito para quatro anos.

Realizada a votação, a proposta foi rejeitada por 309 votos contra 121, com 21 abstenções, entre estas, a do então Constituinte Fernando Henrique Cardoso. O PT votou majoritariamente a favor da proposta. Alguns Constituintes pertencentes a diversos outros partidos, inclusive aos mais conservadores, também apoiaram a proposta, ainda que isoladamente.

Possivelmente, a proposta do Constituinte Maguito Vilela foi uma das que escaparam ao poderoso filtro imposto pelos condutores do processo decisório da Constituinte, a julgar pela resistência desarticulada oposta à sua aprovaçăo. No entanto, uma análise alternativa

7 Reis (2000) ainda se refere aos "adeptos da 'engenharia política', confiantes nas possibilidades transformadoras da ação legal, e 'burkeanos', contrários aos artificialismos dos meios legais"; este artigo bem podia se situar a meio caminho dessas duas últimas correntes.

8 V. Pereira and Muller (2004). 
poderia sugerir que a sua submissão foi proposital, uma vez que nela se entrevia o grave defeito da omissão em relação à duração do mandato dos Deputados Federais, apesar da evidente vinculação das matérias.

Para uma proposta que contrariava os planos para o futuro imediato da maioria dos Constituintes, fato que foi habilidosamente acenado pelo Relator, esse caráter assistemático foi fatal para a proposta. Com a pauta de votações bastante extensa, a rejeição significou também o esgotamento do assunto como matéria vencida.

\section{Modelos envolvendo a duração de mandatos políticos}

Tem sido crescente a adoção de modelos baseados na assimetria de informação entre os eleitores e os políticos no exercício do mandato para explicar o relacionamento entre esses dois grupos de agentes. Nesses modelos, o Principal (eleitores) não tem informação sobre o nível de esforço que o Agente (o político) empregará no serviço que deverá prestar ao Principal. Esforço é o termo genérico utilizado em teoria da informação para designar o desvio de conduta dos políticos no exercício do mandato. Esses desvios podem ser interpretados de modo amplo. Podem referir-se à perseguição exclusiva do interesse particular, ainda que conflitante com o dos eleitores, pelo político, como também à prestação de serviços eleitorais de alto custo para os eleitores, como a aprovação de projetos ineficientes, o uso do poder de influência sobre a burocracia para liberação de vantagens, a troca de favores entre os políticos etc.

A utilidade desses modelos é que se pode centrar o foco no relacionamento entre os eleitores e os políticos, entendido como determinante do controle eleitoral realizado pelos eleitores. O comportamento dos eleitores não se caracteriza pela escolha dos melhores candidatos disponíveis numa eleição, como querem os clássicos, eles apenas mantêm os melhores incumbentes e substituem os piores, a partir da observação do resultado da atividade parlamentar. Essa é a hipótese principal do primeiro modelo a seguir.

Em seguida, desenvolve-se um modelo, também baseado na seleção por competência, para verificar que implicações teria o tamanho dos mandatos sobre uma variável relevante, como reconhece a literatura, que é a senhoridade média dos políticos, isto é, o estoque de experiência dos políticos que compõem uma casa legislativa. Para abordar a questão dos custos de campanha e da competitividade, lança-se mão de outro modelo clássico de informação incompleta, que é o modelo de Shapiro-Stiglitz. 


\subsection{Um modelo de agenciamento}

$\mathrm{Na}$ formulação mais usada, advinda da moderna teoria positiva da regulação," os eleitores observam o valor total dos benefícios ou transferências totais, $T$, que lhes foram proporcionadas pela atuação do político, mas têm informação incompleta sobre o custo em que incorreram para a obtenção desses benefícios. Esse custo refere-se, por exemplo, ao retorno em inflação ou aumento de impostos que a aprovação de um projeto pode provocar. Outros resultados indesejados são a utilização ineficiente de recursos, o aumento no nível de corrupção, atraso no pagamento dos salários do funcionalismo, etc. Esse custo $(C)$ é dado pela seguinte expressão

$$
C=\beta-e
$$

onde, $\beta$ é um parâmetro de eficiência do político, imperfeitamente observado pelos eleitores, e $e$ é o nível de esforço escolhido pelo político e constitui sua informação privada.

Deve-se lembrar que $\beta$ é um parâmetro apenas no curto prazo. $\mathrm{Na}$ formulação original de Peltzman (1976), $\beta$ é uma função do número de eleitores beneficiados pela atividade do político. Esse autor achava que quanto mais pessoas o político pretendesse alcançar com as transferências maior seria o custo social dessas transferências, o que pode, parcialmente, explicar as diferenças nas taxas de reeleição dos estados brasileiros com maior restrição de representatividade. Dick e Lott (1993) ampliaram o leque de variáveis capazes de influir em $\beta$. Para eles, a senhoridade média de uma casa legislativa, isto é, o tempo médio de exercício de todos os representantes, e a senhoridade do político individual votado em um distrito ou por um conjunto de eleitores influiriam da seguinte maneira naquele parâmetro:

$$
\beta=\beta(n, S, \bar{S}), \quad \partial \beta / \partial n>0, \quad \partial \beta / \partial S<0 e^{\partial \beta} / \partial \bar{S}>0
$$

$\mathrm{O}$ modelo que é desenvolvido a seguir procura prover uma rationale para a equação (1) usada na simulação feita no início deste trabalho e para o comportamento de seleção por competência adotado pelos eleitores, ali assumida. Trata-se de uma versão simplificada e determinística dos modelos que assumem a assimetria de informação entre o Principal e o Agente e segue estreitamente o desenvolvimento feito por Laffont e Tirole (Cap. 2, 1993). Inicialmente, o modelo é desenvolvido com informação completa, evoluindo depois para a

${ }^{9}$ Vide Laffont e Tirole (1993). 
existência de assimetria de informações, para que as diferenças nos resultados fiquem mais visíveis.

Com informação completa, os eleitores observam $C$ e conhecem o parâmetro $\beta^{10}$ na expressão (3). A utilidade dos políticos é dada, unicamente, por $U=t-\psi(e)$, onde $t$ representa o retorno em apoio político que o representante recebe de seus eleitores em virtude de sua atuação. A função $\psi(e)$ denota a desutilidade do esforço despendido pelo político buscando reduzir o custo das transferências feitas para os eleitores. Assume-se que $\psi^{\prime}()>0,. \psi^{\prime \prime}()>$.0 e $\psi(0)=0$.

A restrição de racionalidade individual exige que a utilidade do político seja pelo menos igual a uma utilidade mínima, que se normaliza para zero. Assim, tem-se:

$$
U=t-\psi(e) \geq 0
$$

O eleitorado, ou um eleitor representativo, avesso ao risco, deriva sua utilidade das transferências líquidas propiciadas pela ação do político, mas desconta desse valor o apoio t que deve dar, em troca, ao político. Esse apoio pode ser entendido como um custo de oportunidade ou como resultante de um esforço gasto no monitoramento dos políticos, cujo valor é assumido como igual ao apoio percebido pelo político. A função-objetivo dos eleitores $(W)$ é então dada por:

$$
W=T-t-C=T-t-\beta+e
$$

O problema dos eleitores é então maximizar (5) sujeita a (4). Note-se que isso significa que o eleitorado preocupa-se apenas em que o político permaneça no jogo, dando peso zero ao seu ganho de utilidade. Por isso, a expressão (4), na verdade, é uma igualdade. Assim, $t=\psi(e)$, e, dessa forma, o eleitorado tem o poder de determinar o nível de esforço do seu representante. Seu pioblema consiste em maximizar diretamente a seguinte expressão:

$$
\max _{e} T-\psi(e)-\beta+e
$$

a solução desse problema é:

$$
\begin{aligned}
& \psi^{\prime}(e)=1 \text { e } e \equiv e^{*} \\
& \mathrm{U}=0 \text { ou } t=\psi\left(e^{*}\right)
\end{aligned}
$$

10 Uma situação que se assemelha à prescrita nos textos políticos clássicos (como em J.S. Mill e Rousseau, segundo Lau e Redlawski, 1997), segundo a qual uma democracia, para funcionar, exige que o cidadão médio se interesse por política, preste atenção aos seus temas, discuta-os e participe ativamente do processo politico. 
O custo, em equilibrio, seria e o contrato ótimo para o eleitorado, a ser oferecido aos políticos, seria $\left\{t=\psi\left(e^{*}\right), e=e^{*}\right\}$, ou seja, os eleitores oferecem suporte eleitoral igual a $\psi\left(e^{*}\right)$ em troca de um nível de esforço igual a $e^{*}$. Alternativamente, como sugerem Laffont $\mathrm{e}$ Tirole, os eleitores podem oferecer aos políticos um menu linear de contratos em função da variável observável $\mathrm{C}$, da seguinte forma:

$$
t(C)=\psi\left(e^{*}\right)-\left(C-C^{*}\right)=\psi\left(e^{*}\right)-\left(C-\beta+e^{*}\right),
$$

que os políticos colocam na sua função de utilidade (4), que se torna:

$$
U(e)=\left(e-e^{*}\right)-\left(\psi(e)-\psi\left(e^{*}\right)\right)
$$

a qual, por sua vez, é maximizada quando $\psi^{\prime}(e)=1$ ou $e=e^{*}$.

As expressões (8) e (9) já dão à equação (1) uma maior solidez em termos de racionalidade, mas essa discussão pode ser adiada para depois do desenvolvimento a seguir, que relaxa a hipótese de informação completa por parte dos eleitores. Os eleitores não observam o tipo do político. Sabem apenas que eles podem ser um de dois tipos, o mais eficiente, $\beta$ que ocorre com probabilidade conhecida v, e o menos eficiente, $\beta$, que ocorre com probabilidade (1-v). Assim, $\bar{\beta}>\beta$ e toma-se a diferença como $\Delta \beta=\bar{\beta}=\underline{\beta}$. O esforço continua sendo informação privada do político.

Os eleitores têm interesse em revelar o tipo dos políticos e procuram por um equilibrio separador, em que os políticos não consigam esconder ou dissimular os seus tipos (princípio da revelação). Dessa forma, o eleitorado poderá, se lhe convier, separar os menos ineficientes. Supondo que tal equilíbrio exista, usa-se um traço acima ou abaixo de cada variável para caracterizar sua vinculação com o tipo do político, por exemplo, $\underline{e}$ e $\bar{e}$ referem-se ao esforços despendidos, em equilibrio, pelos políticos mais e menos eficiente, respectivamente).

Para assegurar a revelação, os eleitores verificam as restrições de compatibilidade de incentivos $(\mathrm{CI})$, que são as seguintes:

$$
\begin{aligned}
& \underline{t}-\psi(\beta-\underline{C}) \geq \bar{t}-\psi(\underline{\beta}-\bar{C}) \\
& \bar{t}-\psi(\bar{\beta}-\bar{C}) \geq \underline{t}-\psi(\bar{\beta}-\underline{C})
\end{aligned}
$$

Somando essas equações, obtém-se:

$$
\psi(\beta-\bar{C})+\psi(\bar{\beta}-\underline{C})-\psi(\beta-\underline{C})-\psi(\bar{\beta}-\bar{C}) \geq 0
$$


ou

$$
\int_{\underline{C} \underline{\underline{\beta}}}^{\bar{C}} \int^{\bar{\beta}} \psi^{\prime \prime}(\beta-C) d \beta d C \geq 0
$$

Como $\psi^{\prime \prime}()>$.0 e $\bar{\beta}>\beta$, a integral dupla acima implica que $\bar{C}>\underline{C}$. Em equilíbrio, o custo social do político ineficiente é maior que o do político eficiente.

As condições de racionalidade individual (RI) são as seguintes:

$$
\begin{aligned}
& \underline{U}=\underline{t}-\psi(\underline{e}) \geq 0 \\
& \bar{U}=\bar{t}-\psi(\bar{e}) \geq 0
\end{aligned}
$$

A CI do tipo eficiente (expressão (10)), juntamente com a IR do político ineficiente (expressão (13)), implica a RI do político eficiente. Para ver isso, e notando que, por (13), $\psi(\bar{e})=\psi(\bar{\beta}-\bar{C}) \leq \bar{t}$, parte-se da RI do tipo eficiente:

$$
\begin{aligned}
\underline{t}-\psi(\underline{\beta}-\underline{C})=\underline{U} & \geq \bar{t}-\psi(\underline{\beta}-\bar{C}) \\
& \geq \psi(\bar{\beta}-\bar{C})-\psi(\underline{\beta}-\bar{C}) \\
& \geq 0
\end{aligned}
$$

A CI do tipo eficiente pode também ser reescrita como:

$$
\begin{aligned}
\underline{U} & \geq \bar{t}-\psi(\underline{\beta}-\bar{C}) \\
& \geq \bar{t}-\psi(\bar{\beta}-\bar{C})+\psi(\bar{\beta}-\bar{C})-\psi(\underline{\beta}-\bar{\beta}+\bar{\beta}-\bar{C}) \\
& \geq \bar{U}+\psi(\bar{e})-\psi(\bar{e}-\Delta \beta)=\bar{U}+\Phi(\bar{e})
\end{aligned}
$$

onde $\Phi(e)=\psi(e)-\psi(e-\Delta \beta)$ é uma função crescente, já que $\psi^{\prime \prime}()>$.

Os eleitores maximizam sua função-objetivo sujeita às restrições (11), (13) e (14). As restrições (13) e (14) são limitantes porque é sempre do interesse do Principal restringir a extração de rent por parte dos Agentes. Rent é custoso para os eleitores. Tomando essas desigualdades como igualdades e adotando-se a estratégia de procurar uma solução apenas com elas, verificando-se depois se ela atende à restrição (11), o problema dos eleitores passa a ser o seguinte: 


$$
\max _{t, \bar{t}, e, \bar{e}} v(T-\underline{t}-\underline{\beta}+\underline{e})+(1-v)(T-\bar{t}-\bar{\beta}+\bar{e})
$$

sujeita a:

$$
\begin{aligned}
& \bar{t}-\psi(\bar{e})=0 \Rightarrow \bar{t}=\psi(\bar{e}), \mathrm{e} \\
& \underline{t}-\psi(\underline{e})=\Phi(\bar{e}) \Rightarrow \underline{t}=\psi(\underline{e})+\Phi(\bar{e})
\end{aligned}
$$

Fazendo-se a substituição de $t$ e $\bar{t}$ na função-objetivo, a maximização se torna possível e os resultados são os seguintes:

$$
\begin{aligned}
& \psi^{\prime}(\underline{e})=1 \text { ou } \underline{e}=e^{*} \\
& \psi^{\prime}(\bar{e})=1-\frac{v}{1-v} \Phi(\bar{e})
\end{aligned}
$$

esse último resultado implicando que $\bar{e}<\underline{e}$. Note-se que o político mais eficiente despende um esforço igual ao que despenderia sob informação completa, chamado na literatura de ótimo de primeira classe, mas apropria-se de um rent igual a $\Phi(\bar{e})$. O político menos eficiente não extrai rent ( $\bar{U}=0$ ), mas desenvolve um esforço subótimo em relação à situação com informação completa. As razões podem ser inferidas por meio do gráfico da figura 1 , abaixo, que reproduz o espaço CustoApoio $(C-t)$.

$$
t-\psi(\underline{\beta}-C)=\Phi(\bar{e})
$$

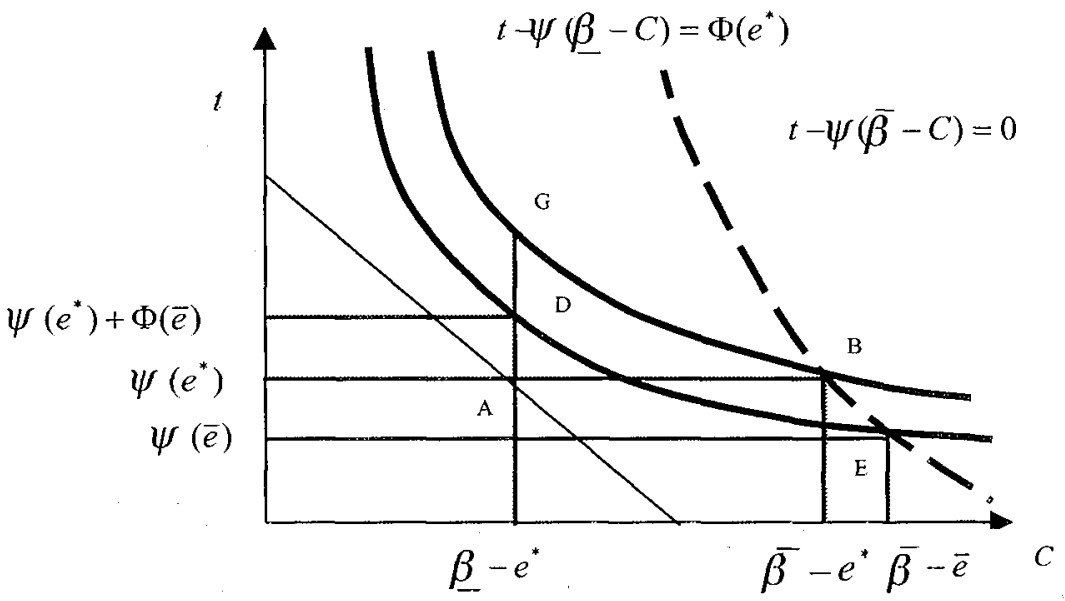

Figura 1

178 Revista Análise Econômica, Porło Alegre, ano 24, n. 46, p. 165-198, setembro de 2006. 
Suponha-se que o tipo $\underline{\beta}$ tenha sido o único tipo de político no modelo com informação completa. Um agente desse tipo estaria, por exemplo, no ponto A do gráfico. Se os eleitores oferecem o único contrato da situação com informação completa, $t=\psi s\left(e^{*}\right)$, ambos os tipos de políticos iriam para o ponto $B$, onde se observaria um esforço subótimo do tipo mais eficiente, que extrairia uma quantidade maior de rent do que no contrato representado por (14) e (15), e um esforço ótimo do político menos efiente, que não ficaria com nenhum rent. Para obter o esforço ótimo do tipo mais eficiente, os eleitores oferecem o contrato $\mathrm{E}$ aos políticos menos eficientes. Assim, os políticos eficientes são indiferentes em moverem-se para $E$ ou para $D$, que é o contrato para eles desenhado. Esse tipo perde, assim, o incentivo de se fazerem passar pelo outro tipo. Em essência, esse é o princípio da revelação.

A discussão que segue é adequada à subseção seguinte, que se ocupa da vinculação da duração dos mandatos com os resultados do modelo.

\subsubsection{Efeitos da duração de mandatos}

Viu-se que os eleitores podem reconhecer, ex-post, que políticos são do tipo ineficiente, apenas por observá-los se encaminhando para o ponto $\mathrm{E}$ do gráfico. Uma primeira questão é saber se os eleitores podem, após as eleições, mudar o menu de contratos oferecido aos políticos. Obviamente, podem. Não há qualquer vinculação anterior com o político que não possa ser rompida pelos eleitores na próxima eleição, com exceção dos direitos de propriedade sobre o mandato, assegurados legalmente. É diferente, por exemplo, de um contrato de concessão ou obra pública, em que a autoridade concedente ou contratante está presa aos termos da convocação.

Se interessa ao eleitorado excluir os políticos ineficientes, basta que lhes seja oferecido o menu linear correspondente à expressão (8), que no caso de informação completa se torna:

$$
t(C)=\psi\left(e^{*}\right)-\left(C-\beta+e^{*}\right)
$$

que corresponde à reta passando pelo ponto A no gráfico da figura 1 .

Diante desse menu, os políticos eficientes se moverão para esse ponto, onde a reta será tangente a sua curva de indiferença nula. Os políticos ineficientes também permanecerão na sua curva de indiferença nula, à direita da reta de contratos. Como não aderem a nenhum contrato, não receberão qualquer apoio dos eleitores e, por isso, 
também não produzirão o bem de valor T para os eleitores. Ficarão, assim, durante todo o mandato, usufruindo de sua utilidade de reserva ( $\bar{U}=0$ ), à espera de serem substituídos na próxima eleição.

A próxima questão é saber se interessa, mesmo assim, remover o tipo ineficiente. Numa perspectiva dinâmica, ou de longo prazo, a resposta é sim, já que depois de um número ilimitado de eleições, todos os políticos do parlamento serão do tipo eficiente e estarão despendendo o esforço ótimo de primeira classe, sem apropriarem-se de qualquer excedente. No curto prazo, a seleção dos políticos ainda pode compensar. Suponha que após a primeira eleição os eleitores ofereçam o menu (17). Imediatamente, os políticos eficientes se moverão para o ponto $\mathrm{A}$, enquanto os do tipo ineficiente deixarão de produzir. Essa situação será preferível se, e somente se a seguinte desigualdade se verificar:

$$
v\left(T-\psi\left(e^{*}\right)-\boldsymbol{\beta}+e^{*}\right) \geq v\left(T-\psi\left(e^{*}\right)-\Phi(\bar{e})-\underline{\beta}+e^{*}\right)+(1-v)(T-\psi(\bar{e})-\bar{\beta}+\bar{e})
$$

Os lados dessa desigualdade são formados pelas funções-objetivo dos eleitores nas situações com seleção e sem seleção dos políticos, respectivamente. Ambos os lados são funçōes lineares do valor T do bem produzido por cada político, a saber:

$$
\begin{aligned}
& W=v T+v\left(-\psi\left(e^{*}\right)-\underline{\beta}+e^{*}\right) \\
& W=T+v\left(-\psi\left(e^{*}\right)-\Phi(\bar{e})-\underline{\beta}+e^{*}\right)+(1-v)(-\psi(\bar{e})-\bar{\beta}+\bar{e})
\end{aligned}
$$

No gráfico da Figura 2, pode-se ver que a desigualdade (BB) só prevalece para baixos valores de $T$. Se a magnitude de $T$ for suficientemente pequena, a seleção por competência interesserá aos eleitores mesmo no curto prazo. Se o valor de $T$ for alto, é melhor para os eleitores permitir uma situação de esforço subótimo para os políticos ineficientes e de extração de rent por parte dos políticos eficientes.

O que dizer, então, da magnitude de T? Laffont e Tirole consideram que, se existem substitutos e o custo de substituição é pequeno, o valor de $T$ é pequeno. "A competição reduz o excedente social da produção (da firma regulada)", dizem. No meio político, pelo menos, substitutos é que não faltam. A atividade política é indispensável, mas os políticos, tomados individualmente, sobretudo os que pertencem ao tipo ineficiente, claramente não são indispensáveis. Esse argumento sugere que o valor de $T$ no modelo não seja alto e que, mesmo no curto prazo, há motivação para que os eleitores realizem a seleção por competência de seus representantes.

No modelo, a variável $T$ tem um caráter nitidamente unidimensional, adequado à captura do retorno gerado por firmas sujeitas a regulação de uma agência pública, por exemplo. É possível exigir de 
cada firma a produção de um bem com o mesmo valor, $T$. Em política, o resultado da atividade dos políticos pode tomar diversas formas, sujeitas a avaliação sob múltiplos critérios, de caráter ideológico, partidário e pragmático. Usualmente, os modelos políticos referem-se à variável $T$ como representativa do valor total das transferências de renda direcionadas pelos políticos aos seus eleitores. Se os eleitores valorizam o resultado da atividade política dessa forma, ela se torna um jogo de soma zero e, provavelmente, seria custoso para os eleitores excluir qualquer representante da competição que se instalaria em torno da alocação dos recur'sos públicos.

No entanto, é mais razoável pensar na atividade política como processo de criação de um bem público que se, no seu conjunto, tem um alto valor social, é, no entanto, formado por "unidades construtivas" de menor valor e que podem ser homogeneamente avaliadas. Assim, pode ser desejável que apenas as peças mais eficientes participem do conjunto.

Mais importante nessa discussão é o fato de que o modelo torna claro o papel dos direitos de propriedades associados ao exercício do mandato. A duração do mandato é uma particularidade importante desses direitos já que pode interferir no valor de $T$, aumentando-o. Suponha-se que a magnitude de $T$ seja desdobrável em períodos de mandato e que $n$ seja o número de períodos de mandatos. Se for o valor das transferências em um período, existirá um valor para $n, n_{0}$, tal que para todo $n>n_{0}, n T^{\prime}>T_{0}$, em que $T_{0}$ é o valor mostrado no gráfico da Figura 2, acima do qual os eleitores acomodam os políticos ineficientes. Resulta que quanto mais períodos tiver o mandato, menores serão os incentivos para que os eleitores selecionem os políticos mais eficientes.

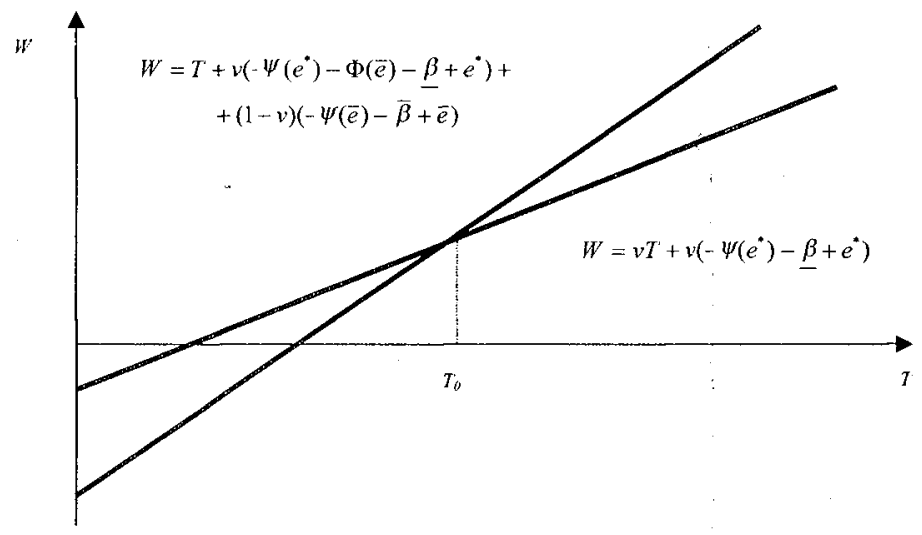

Figura 2

Pinheiro, F. J. Q. ; Almeida, C. L. ; Moreira, T. B. C. Redução de mandatos legislativos... 


\subsection{Senhoridade}

A literatura reconhece amplamente que a experiência legislativa aumenta o poder político da autoridade constituída e, conseqüentemente, a capacidade de atrair benefícios para os constituintes. Dick e Lott (1993) até chamam esse fato de estoque de experiência política de um distrito eleitoral, que no Brasil, seria dos eleitores de um determinado político. No modelo apresentado na seção 3.1, acima, foi mostrado que a senhoridade de um político aumenta sua eficiência em conseguir transferências para seus eleitores, conforme equação (2).

Essa capacidade de atração de benefícios decorre de vários motivos. Um tempo mais longo de exercício proporciona ao político, por exemplo, um maior conhecimento, e assim maior poder de influência, do processo de elaboração do orçamento e da burocracia. Permite também a ascensāo a cargos de maior prestígio nas hierarquias parlamentar e partidária e que contam para as indicações de nomes para a burocracia. Talvez mais importante, o convívio duradouro entre políticos leva ao surgimento de uma rede, cada vez mais complexa, de troca de favores que confere aos participantes grande poder na repartição do bolo orçamentário.

Poder-se-ia argumentar que a fixação de mandatos mais longos poderia favorecer os ganhos advindos da senhoridade. O modelo a seguir desenvolvido procura analisar essa importante questão dos efeitos da reserva de tempo sobre a senhoridade média dos políticos.

Primeiramente, será construído um modelo simplificado em que não há seleção por competência: todos os políticos eleitos para uma instância legislativa, de tamanho $N$, estão sujeitos à mesma probabilidade, $x$, com $0<x<1$, de serem reeleitos, independentemente do tempo anterior no cargo. O processo se inicia no período $t=0$, com a realização da primeira eleição. A senhoridade média dos políticos, $\bar{S}$, é medida, inicialmente, pelo número de mandatos anteriores cumpridos. Posteriormente, consideraremos essa senhoridade média em anos de experiência no cargo. No apêndice mostra-se que a senhoridade média, nesse modelo inicial, evolui de acordo com a seguinte expressão:

$$
\bar{S}_{0}=0, \quad \bar{S}_{i}=x \sum_{j=1}^{i T} x^{j-1}, i_{T}=t+T, \operatorname{com} t=0, T, 2 T, 3 T, \ldots
$$

onde $T$ é o número de períodos entre duas eleições ou a duração dos mandatos. Assim, $i_{T}$ é um índice para cada eleição. Após um número ilimitado de períodos, a senhoridade média dos políticos converge para um valor dado pela seguinte expressão, já que $x \in(0,1)$ : 


$$
\bar{S}_{s s}=\frac{x}{1-x}
$$

Pode-se agora comparar a senhoridade média, em número de períodos $\left(\bar{S}^{\prime}{ }_{r, t r}\right)$, para sistemas eleitorais com durações de mandatos distintos, por exemplo, dois $(T=2)$ e quatro períodos $(T=4)$. A senhoridade limite para um sistema com duração de mandatos igual a dois é $\bar{S}_{2, \infty}^{\prime}=2 x / 1-x$ e a mesma senhoridade para um sistema com duração igual a quatro é $\bar{S}_{4, \infty}^{\prime}=4 x / 1-x$. Assim, se houver convergência de senhoridades, quanto mais longa for a duração de mandatos, maior a senhoridade média da instância legislativa considerada.

Isso não ocorre para o modelo de teste construído na Seção 2 deste estudo. Para aquele modelo, não só a convergência para o nível médio de senhoridade não ocorre, como a senhoridade no sistema com duração de mandatos igual a dois períodos, ao longo do tempo, é maior do que a senhoridade média com duraçāo igual a quatro.

Seria conveniente, então, refinar o modelo acima para permitir a seleção por competência. Isso é feito atribuindo-se probabilidades de reeleição maiores para políticos com mais tempo no cargo. Assim, a probabilidade $x$ sofre um incremento de $R=1+\delta, 0<\delta<1$ para cada mandato já cumprido pelo político. A probabilidade de reeleição de um político com um único mandato continua sendo $\mathrm{x}$, mas a de um político com dois mandatos passa a ser $R x$. Um político com três mandatos cumpridos se reelege com probabilidade $R^{2} x$ e assim por diante. Nessa representação está implícita a noção de que a competência pode ser aferida unicamente pela diferença de senhoridade entre os políticos.

No apêndice, mostra-se que a expressão (3) para a senhoridade transforma-se agora na seguinte fórmula:

$$
\bar{S}_{i r}=x \sum_{j=1}^{i T} C_{j}-1 x^{j-1}
$$

onde os coeficientes $C_{i}$ são funções lineares de potências de $R$. Para $i=4$, por exemplo, tem-se a seguinte expressão para a senhoridade:

$$
\bar{S}_{4}=x\left[1+(2 R-1) x+\left(3 R^{3}-3 R+1\right) x^{2}+\left(4 R^{6}-4 R^{3}-2 R^{2}+4 R-1\right) x^{3}\right]
$$

No apêndice, mostra-se que o termo limite para essa expressão da senhoridade é aproximadamente a seguinte:

$$
\bar{S}_{n}=n R^{\frac{n(n-1)}{2}} x^{n}
$$


que pode ou não ir para zero quando n for muito grande, dependendo dos valores de $\delta$ e $x$. Ou seja, a senhoridade pode não convergir ao longo do tempo.

Para valores muito baixos de $x$, a probabilidade de obtenção de reeleição após um único mandato, a expressão (6) tende a zero quando $n$ for para o infinito. Mas para valores de $x$ acima de 0,2 , a expressão (6) passa a não desvanecer mesmo para pequenos valores de $\delta$. $O$ padrão do desempenho da senhoridade sob os dois regimes é mostrado no gráfico da Figura 3. A senhoridade sob dois períodos é menor do que a de duraçāo quatro no início. A partir de um certo ponto, ela passa a ser sempre maior.

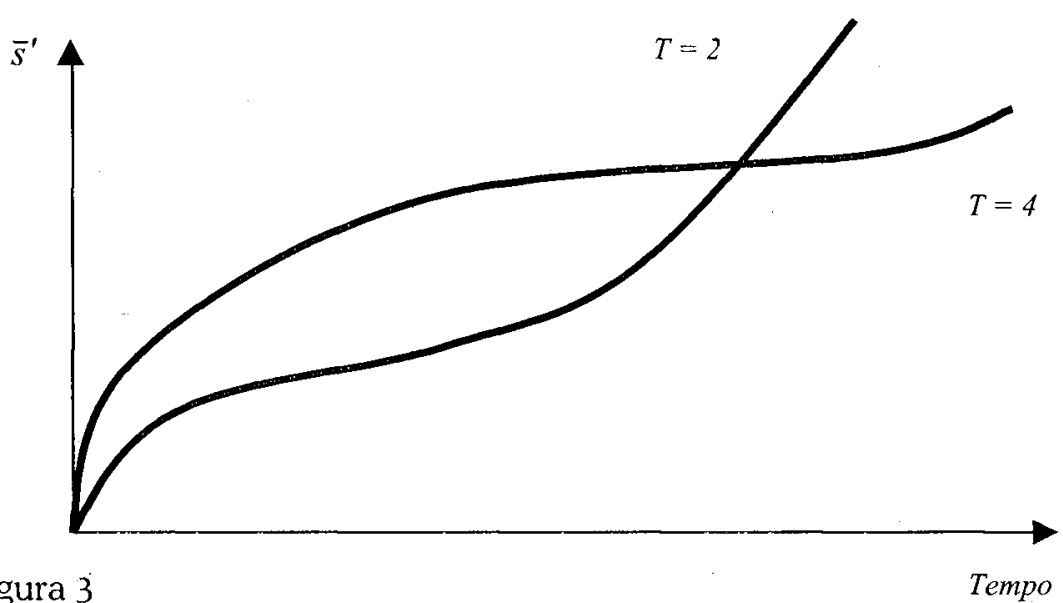

Figura 3

Tempo

A conclusão é de que, assumindo-se a seleção por competência dos políticos, a fixação de mandatos mais longos não implica necessariamente em um ganho maior de senhoridade em relação a regimes com uma menor duração do mandato, principalmente, a longo prazo. Na comparação entre os casos brasileiro e americano, a senhoridade média neste último pode estar bem acima da brasileira, a julgar pela maior taxa de reeleição ali observada ( $76 \%$ contra $49 \%$ no Brasil), o que pode ser uma evidência do comportamento seletivo do eleitorado.

3.3 Barreiras à entrada como fonte de senhoridade

O modelo anterior mostrou que a seleção por competência pode ser fonte de senhoridade independentemente da duração de mandato estabelecida. Porém, é relevante registrar que a literatura também 
admite que os políticos incumbentes, uma vez que preferem estritamente permanecer no mandato a serem substituídos, criam barreiras à entrada para potenciais competidores. A própria supressão da competição eleitoral funciona como a mais eficiente das barreiras à entrada. Assegurada uma longa duração do mandato, o auferimento cumulativo dos benefícios e prerrogativas inerentes ao cargo representa também uma vantagem comparativa em relação aos competidores.

Cox e Katz (1996) citam alguns benefícios inerentes à atividade parlamentar nos Estados Unidos, além de outros que foram sendo criados ao longo do tempo, e que representam uma clara vantagem comparativa para os incumbentes em relação aos potenciais competidores: (a) privilégio de franquia postal, que significa um subsídio postal e que pode ser usado com fins eleitorais; (b) assessoria e infra-estrutura, que podem ser empregadas para a prestação de serviços eleitorais; (c) posição das comissões, que pode ser usada para levantar fundos de campanha; (d) salários e outros privilégios parlamentares que constituem salário indireto; (f) franquia em passagens aéreas, que permite aos parlamentares estar sempre em contato com suas bases eleitorais e (g) influência junto à burocracia administrativa, que pode favorecer o trâmite de processos de interesse de eleitores.

Um postulante a cargo legislativo federal, ou mesmo estadual, poderia, em tese, se beneficiar do afastamento do incumbente da sua base eleitoral, uma vez que estaria este ocupado com as atividades de sua casa. No Brasil, tolera-se amplamente o funcionamento pleno e regular do Legislativo em apenas três dias da semana. A Constituição assegura nada menos de três meses de recesso das atividades parlamentares, durante os quais os parlamentares estão dispensados do comparecimento a sessões. Se o ano é de eleição, tolera-se que votações importantes para o país sejam adiadas para permitir que os parlamentares acompanhem a campanha eleitoral em seus Estados. É até possivel que os políticos no cargo consigam mais tempo livre para dedicar aos seus eleitores do que a grande maioria de seus prováveis competidores.

Outra vantagem relativa da incumbência, apontada por Daniel e Lott (1997), é a de que os custos em formação de capital reputacional são decrescentes ao longo do tempo. Assim, um legislador naturalmente se beneficia dos investimentos anteriores feitos na sua reputação, enquanto os competidores têm que arcar com uma soma maior na criação de um capital reputacional inicial, apto a permitir a competição. Além disso, os parlamentares desfrutam de expressivo espaço na mídia durante os anos de mandato, permitindo-lhes sinalizar convenientemente aos seus eleitores.

É até surpreendente que, com tantas vantagens comparativas a favor dos políticos no cargo, funcionando como barreiras à entrada, o 
Brasil não apresente uma taxa de reeleição mais expressiva, semelhante à verificada nos Estados Unidos. O controle eleitoral realizado pelo eleitorado, em parte, pode explicar esse fato. Outra parte pode ser explicada pelo alto custo das campanhas eleitorais, objeto do estudo a seguir.

\subsection{Competição eleitoral e custos de campanha}

Uma hipótese considerada na literatura é a de que o valor de um mandato legislativo depende dos direitos de propriedade associados ao mandato. Assim, um mandato com duração mais longa vale muito mais do que um de curta duração, já que essa variável é o componente mais sensível desses direitos. A conclusão lógica é a de que a instituição de um mandato com menor duração faria com que o custo das campanhas políticas se reduzissem, causando um aumento da competitividade eleitoral pelo maior número de candidatos em condições de competir.

Essa noção pode ser melhor formalizada a partir do conhecido modelo de Shapiro e Stiglitz (1984). Esse modelo é desenvolvido em tempo contínuo, de modo que algumas variáveis que se referem ao caso discreto têm que ser aproximadas para serem tratadas no modelo contínuo. O modelo permite intuição adicional se for aberta a possibilidade de moral hasard, tal como fizeram aqueles autores. Os pressupostos são os seguintes. Os políticos no exercício do mandato derivam utilidade segundo a seguinte expressão:

$$
U=w-e
$$

onde $w$ denota um salário "político" representativo das vantagens de estar no poder e e é o nível de esforço que devota ao exercício do cargo, que pode assumir apenas dois valores $e=0 \mathrm{e} e=\bar{e}$.

Todos os políticos estão sujeitos a serem destituídos do cargo (derrotados) segundo uma taxa $b / T$ por unidade de tempo. A variável $b$ corresponde a essa taxa no caso discreto. Ela é dividida por $T$, a duração do mandato, para aproximála para o caso contínuo. Os políticos estão na ativa indefinidamente. Se um político exerce esforço $e=0$, fica sujeito a uma taxa adicional de $q / T$ por unidade de tempo de ter seu baixo esforço detectado pelos eleitores e ser removido do cargo. A variável $q$ corresponde à mesma taxa de detecção e remoção no caso discreto, isto é, a cada eleição há a probabilidade $q$ de que o político com baixo esforço seja derrotado. Essa probabilidade é dividida pelo tamanho do mandato, $T$, em número de períodos, como uma aproximação do seu valor no caso contínuo.

A dedução do valor presente de um mandato político leva em conta a possibilidade de que o político permaneça indefinidamente no 
cargo. A utilidade de reserva dos políticos, isto é, a utilidade de não estar no poder, é normalizada para $U_{0}=0 . O$ valor do mandato é calculado por um político que despende esforço $e=\bar{e}\left(U_{e}\right)$ e por outro que não despende nenhum esforço $\left(U_{s}\right)$. A dedução desses valores é intuitiva: ${ }^{11}$

$$
\begin{aligned}
& \rho U_{e}=(w-\bar{e})-b\left(U_{e}-U_{0}\right) ; \mathrm{e} \\
& \rho U_{s}=w-\left(b+\frac{q}{T}\right)\left(U_{s}-U_{0}\right)
\end{aligned}
$$

Essas equações dizem que o valor presente do mandato para cada situação de esforço, quando multiplicada por uma taxa de retorno por unidade de tempo vigente na economia, $\rho$, deve ser igual ao beneficio líquido esperado, por unidade de tempo, de estar no mandato. Isolando os valores presentes dos mandatos, chega-se às seguintes expressões:

$$
\begin{aligned}
& U_{e}=\frac{w-\bar{e}}{\rho+b / T} \\
& U_{s}=\frac{w}{\rho+(b+q) / T}
\end{aligned}
$$

Essas equações mostram, com clareza, que o valor do mandato cresce com o aumento de $\mathrm{T}$. Adicionalmente, verifica-se que o valor do mandato com esforço tende a superar o valor com esforço quando $T$ é muito grande, independentemente da magnitude de q, que é a probabilidade de o político ser flagrado ou percebido como ocioso. Significa que um aumento na duração dos mandatos aumenta também os incentivos para despender pouco esforço. Essa situação é mostrada no gráfico da Figura 4, abaixo, cuja configuração assume um valor suficientemente grande de $q$ em relação $a b$.

Se o valor dos mandatos se reduz com a diminuição da duração dos mandatos, evidentemente, o investimento máximo economicamente justificável numa campanha também diminui. A literatura admite que só uma parte do capital investido numa campanha toma a forma de capital financeiro, uma parte desse capital é de natureza reputacional, que é o estoque de informações que a sociedade dispõe a respeito de um candidato. $\mathrm{Na}$ verdade, os gastos financeiros de campanha objetivam dotar a sociedade de informações suficientes sobre o

${ }^{11}$ V. Romer (1996), pág. 454

Pinheiro, F. J. Q. ; Almeida, C. L. ; Moreira, T. B. C. Redução de mandatos legislativos... 
candidato e, dessa forma, podem ser vistos como complementares ao estoque social de informações no início da campanha.

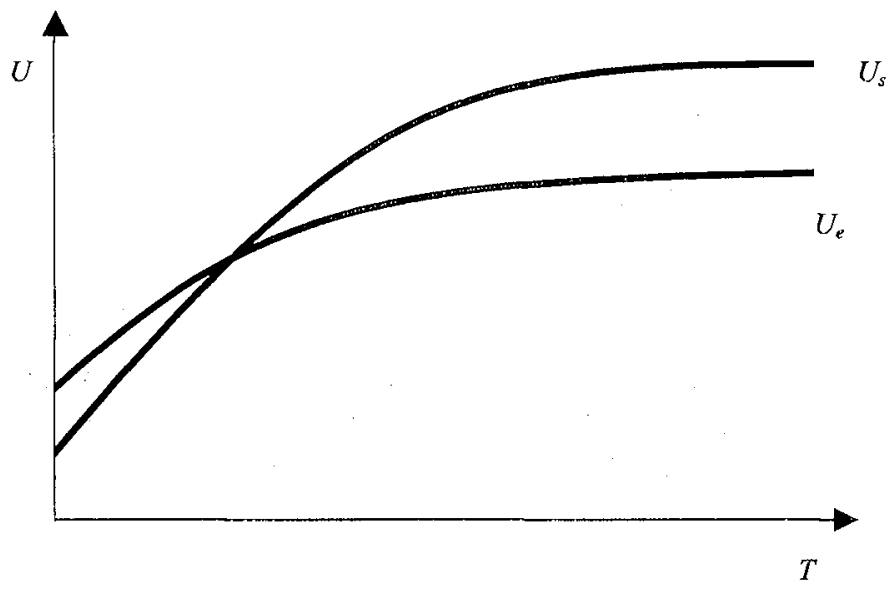

Figura 4

Desse modo, é lícito concluir que, se o valor do mandato diminui devido a uma redução de mandatos, essa mudança também beneficia os candidatos que, mesmo possuindo estoque reputacional relevante, não se dispunham à competir por não dispor dos recursos financeiros necessários à complementação de um capital eleitoral mínimo. Como essa exigência de complementação torna-se menor com a redução de mandatos, é de se esperar que a medida aumente também a competitividade eleitoral pela maior participação de candidatos com histórico de serviços prestados à sociedade.

Dados empíricos relatados por Daniel e Lott (1997), embora relacionados com a imposição da limitação de mandatos, confirmam tanto a assertiva da diminuição do custo das campanhas, como a de aumento da competitividade. Segundo relatam esses autores, dados em seção transversal referentes à disputa para cargos de governador nos Estados Unidos confirmam a hipótese de redução dos custos de campanha. Pesquisas posteriores, feita com dados em séries temporais e em seção transversal, referentes a eleições para representantes nas Casas Estaduais (equivalentes a Deputados Estaduais), senador e governador confirmaram os resultados iniciais. Referindo-se às eleições para o cargo de representante nas Casas estaduais, os mesmos autores acharam que a limitação de mandatos reduziu "dramaticamente" os gastos com campanhas eleitorais. É importante notar que esses efeitos 
são operados pela única via da redução do valor do mandato, que também é causada pela limitação de mandatos, daí a pertinência desses dados empíricos com a redução de mandatos.

Com relação ao aumento da competitividade, são ainda Daniel e Lott (1997) que chegaram a robustos resultados, segundo os quais, após a introdução do limite de mandatos no estado da Califórnia, mais candidatos surgiram na disputa em relação ao período em que não havia o controle, mais incumbentes foram derrotados, as disputas são mais apertadas e a quantidade de distritos com candidatura única diminuiu.

\section{Equilbrio de poder entre Legislativo e Executivo}

Os projetos de interesse do Executivo têm que ser constantemente negociados com o Legislativo, e a sua execução deve estar sujeita ao estrito controle do parlamento. O controle eleitoral exercido pelo eleitorado pode, então, influir sobre os resultados da administração, dando ou negando maioria ao Executivo no Parlamento. Esse tipo de controle é conhecido na literatura como voto dividido (vote splitting).

Bugarin (1999) aponta que o voto dividido funciona como um seguro do eleitorado contra as incertezas do futuro. Conceder a maioria do Parlamento ao partido ou governante que controla o Executivo corresponde, em grande medida, a um governo unificado. $O$ executivo passa a dispor de maior facilidade para obter apoio a seus projetos. Dividindo seu voto, o que o eleitorado faz é aumentar a dificuldade de negociação entre Parlamento e Executivo, eliminando a parte da plataforma mais sujeita a dissensões no meio político.

No Brasil, uma legislatura sempre se inicia com a votação de um novo Executivo e de um novo Parlamento, limitando a capacidade do eleitorado de influir na administração do país, dividindo ou unificando seu voto.

É forçoso notar, também, que a não existência desse mecanismo de controle eleitoral no país o distingue fortemente das modernas democracias do mundo desenvolvido.

Uma aliança entre o Executivo e o Legislativo pode durar até quatro anos, sem que o eleitorado possa ter condições de, pelo voto, alterar os termos do acordo. As implicações disso para a fé democrática da parcela dos eleitores derrotada nas urnas não é desprezivel.

Os oposicionistas mais moderados chamam essa situação de jogo trancado de cesarismo. Os mais exaltados simplesmente passam a duvidar do próprio processo democrático como melhor forma de 
equacionamento dos problemas sociais. Essas tentativas de deslegitimação democrática são, evidentemente, fontes de instabilidade política. Pior se, no transcurso da legislatura, as pesquisas de opinião indicarem insatisfação com o governo. O sentimento coletivo de impotência democrática poderá colocar em risco a própria estabilidade das instituições.

A redução de mandatos, permitindo mais de uma legislatura em um mesmo mandato executivo, funcionaria como uma válvula de alívio de tensões políticas que surgem constantemente. Os parlamentaristas defendem que justamente esses momentos de maior tensão política seriam melhor superados com a mudança de sistema. Mas é natural supor que a mudança traria também um acirramento da disputa política, o que, juntamente com a inadaptação ao novo sistema, poderia transformar-se, no curto prazo, em novo foco de instabilidades.

\section{Por que inexiste debate sobre redução de mandatos no Brasil?}

Percebe-se que, na atual fase de reavivamento das questões políticas motivadas pelo intento de reforma o sistema político nacional, praticamente não há debate sobre questões ligadas aos direitos de propriedade associados ao exercício de mandatos legislativos. Basta que se observe as idéias em voga: voto distrital, parlamentarismo, financiamento público de campanhas, fidelidade partidária etc. Essa ausência de debate sobre questões ligadas aos direitos de propriedade revela o confinamento do debate aos titulares desses direitos de propriedade, principais interessados em mantê-los indisponiveis, já que uma longa duração de mandatos representa uma poderosa barreira à entrada de potenciais competidores.

Prova disso é que, confrontados com a oportunidade de um debate sobre a duração de mandatos, por ocasião da elaboração da Constituição atualmente, em vigor, as discussões sobre a matéria foram praticamente nulas, e a uma única emenda tratando do assunto, apresentada sem a precisão técnica e o necessário respaldo que um efetivo debate de alcance social poderia propiciar, foi sumariamente rejeitada pelos constituintes.

No campo partidário, observa-se que nenhum partido político apoia abertamente a redução de mandatos legislativos. Pelo lado da coalizão de partidos de centro e de direita, que abrigam a maior parte dos políticos profissionais, propor emendas redutoras de mandato é contrariar diretamente o interesse eleitoral desses polí sos. Entre os partidos de esquerda, incluindo o partido que apresentou uma tendência 
majoritária de apoio à emenda, o debate em torno da questão não é dos mais ativos. Esses partidos são motivados também por objetivos estratégicos de curto prazo que já os levaram a não apoiar nem o voto distrital (em que o voto ideológico seria prejudicado pelas práticas clientelistas de muitos distritos no interior do país) nem a emenda da reeleição (que beneficia seus adversários postados no Executivo). Com um fiel e significativo, embora não majoritário, eleitorado ideológico, que lhes dá uma força eminentemente parlamentar, não seriam os partidos de esquerda que liderariam o movimento pela redução de mandatos, algo que reduziria, de imediato, o valor total de seu patrimônio político.

Entre os novos políticos que almejam a eleição, que sentem mais de perto a dificuldade de competição com os políticos no poder, não há defesa notável de uma proposta de redução de mandatos. Uma explicação é de que os postulantes valorizam esses cargos com base nos direitos de propriedade que já se encontram assegurados na legislação. Eles não aspiram a cargos com dois anos de mandatos, de baixo custo e alta competitividade, e sim a cargos com quatro anos de mandato, de alto custo, mas baixa competitividade.

Uma explicação alternativa, natureza circular, é de que os competidores não propõem a redução de mandatos porque não existe debate nenhum sobre o assunto. A receptividade no eleitorado seria pequena pela ausência total de discussão prévia necessária à construção de uma base de convicção capaz de tornar plausível uma proposta eliminadora de privilégios tão enraizados. Sem uma base de opiniões bem fundamentadas no meio social, qualquer proposiçăo que ataque interesses tão fortes passa facilmente por gratuita, oportunista ou até esdrúxula.

$\mathrm{Na}$ esfera popular, há uma nítida predileção pelos chamados critérios "fortes" de responsabilização política, ${ }^{12}$ a serem aplicados aos casos de desvio no exercício da representação política, que é o problema básico das democracias representativas modernas. ${ }^{13}$ Critérios fortes são aqueles que se empregam no transcorrer da delegação, de modo terminativo, como o voto de desconfiança tão caro aos parlamentaristas, o mecanismo do recall de que falam os adeptos do voto distrital e os institutos do impeachment, cassação, inelegibilidade e outros que possam ser criados pelo sistema legal.

12 Para uma abordagem sucinta dessa temática, ver Aydos (2000).

13 Trata-se de um problema único, como em Bugarin (2000) e como advoga-se neste trabalho. Outros autores desdobram esse problema e vêem conflito entre autenticidade da representação e governabilidade, como Reis (2000), e entre direitos individuais e tendência dos governantes à opressão, como Aydos (2000). 
No processo de decisão do emprego desse tipo de critério, há um sensível predomínio das instituições, ainda que representativas da sociedade, o que antes de elitismo, pode resultar da baixa confiança no processo de controle eleitoral exercido pelos eleitores. É possível notar uma certa circularidade nessa relação de causalidade. Enquanto não se adotam medidas que intensifiquem o controle eleitoral dos políticos, por não se acreditar que ele produza os resultados esperados, a impaciência da sociedade com os casos extremos de desvio se exacerba, o que leva, por sua vez, à primazia das propostas de controles fortes em detrimento das medidas que privilegiem o controle eleitoral.

A academia, que é o setor livre de todos os contingenciamentos que impedem o surgimento de um debate sobre a redução de mandatos, tende a responder à demanda social por proposições de critérios fortes de controlabilidade política. Assim, os recursos analíticos disponíveis, que não são muitos diante da grande complexidade inerente aos temas políticos, como sugere Reis (2000), são todos aplicados na busca de propostas que dêem resposta imediata aos anseios sociais. Com o desenvolvimento de recursos analíticos inovadores, provenientes de áreas de pesquisa recentes nos campos da ciência política e da economia política, espera-se que a atual deficiência de estudos políticos sobre os direitos de propriedade associados a mandatos políticos seja suprimida.

\section{Conclusão}

A simulação em computador do modelo apresentado no início deste estudo, baseado na seleção por competência e no voto racional dos eleitores, hipóteses assumidas ao longo deste trabalho, revelou uma convergência do índice médio de desempenho para um valor superior à média da população de políticos potenciais e um aumento da taxa de reeleição ao longo do tempo. Esse último resultado sugere a adoção dessa taxa como um indicador de maturidade de um sistema político.

De fato, estudos feitos para os Estudos Unidos, país com tradição democrática secular, revelam a ocorrência de altas taxas de reeleição. Esse fato, juntamente com o resultado da convergência para níveis superiores de desempenho, podem explicar porque os países desenvolvidos da Europa de longa tradição democrática e de sistema parlamentarista de governo adotam duração de mandatos similares às verificadas no Brasil. $O$ incentivo para alterar a duração de mandatos nesses países pode ser pequeno devido ao estágio avançado de maturidade democrática por eles alcançado. Portanto, o recurso à comparação com as constituições políticas desses países, amplamente utilizado na discussão sobre itens da reforma política no Brasil, pode ser o mais adequado. 
O resultado do teste empírico sobre dados das duas últimas eleições realizadas nos estados para escolha dos Deputados Federais demonstrou que o viés da representação dos estados na Câmara existente no Brasil é capaz de explicar as diferenças nas taxas de reeleição dos diversos estados brasileiros. Os estados com o menor número de cadeiras na câmara por eleitor apresenta taxas de reeleição mais altas. Esse resultado tem aderência com a hipótese da preferência do político por permanecer no cargo, que não afasta a de seleção por competência. Por outro lado, as diferenças de renda per capita não explicam as diferentes taxas de reeleição, indicando uniformidade do comportamento dos eleitores brasileiros. O componente ideológico, medido na forma descrita na Seção III, mostrou não ser determinante da exis“ tência de diferenças entre as taxas de reeleição.

É importante destacar que os resultados alcançados com a simulação e os testes empíricos militam a favor da hipótese de seleção por competência e voto racional dos eleitores. Uma sugestão para pesquisa futura relevante é a de realização de testes específicos que conduzam a resultados mais robustos nesse sentido, de modo a abater a noção, bastante disseminada, de que os eleitores brasileiros não votam corretamente.

O desenvolvimento de um modelo teórico com base na literatura sobre teoria da informação sugere que quanto maior a duração de mandatos, maior o incentivo para que o eleitorado acomode os políticos menos competentes no exercício do cargo e que, pelo contrário, com uma duração mais curta, a tendência é a de que os eleitores realizem a seleção por competência, afastando os políticos ineficientes.

Adotando-se um modelo de seleção por competência para análise do comportamento do estoque de experiência dos políticos (senhoridade), verificou-se que, não necessariamente, a adoção de mandatos mais longos leva a uma maior senhoridade. No longo prazo, especialmente, é provável que mandatos mais curtos é que levem a uma maior senhoridade dos políticos.

No que tange à abordagem sobre o valor dos mandatos políticos, o modelo construído, baseado na conhecida configuração de Shapiro e Stiglitz, mostrou que uma duração maior para os mandatos políticos, aumenta o valor do mandato exercido sem esforço pelo político, relativamente ao exercido com esforço, aumentando, dessa forma, o incentivo para o comportamento sem esforço. A diminuição no valor dos mandatos políticos, induzida pela redução do tamanho do mandato, pode levar a uma menor interferência do poder econômico nas campanhas eleitorais e a uma maior competitividade entre os políticos, como apontam as evidências empíricas disponíveis para os Estados Unidos. 
Este artigo procurou também enfatizar que a longa duração de mandatos legislativos no Brasil pode funcionar como eficiente barreira à entrada de novos políticos e estar suprimindo um importante instrumento de controle eleitoral, que é o voto dividido, afastando o país, nesse ponto específico, da prática internacional democrática relevante.

Finalmente, não se pode esperar que haja uma intensificação do debate sob impulso advindo dos círculos políticos. Os objetivos, tanto de longo, como de curto prazo, ali imperantes não comportam uma discussão efetiva sobre a redução de mandatos legislativos. Isso explica em boa medida a insuficiência de um debate sobre questões com repercussões tão poderosas sobre o produto político do país, apesar do fácil apelo que a proposta poderia ter junto ao detentor originário de todo o poder político, que é a sociedade, caso ela estivesse razoavelmente informada. $\mathrm{O}$ objetivo deste artigo é justamente se juntar à incipiente literatura nacional nesse campo, de modo a gerar o debate prévio necessário à criação de convicções a respeito do tema aqui tratado.

\section{Referências}

ADAMS, J. Condorcet efficiency and the behavioral model of the vote. The Journal of Politics, 1997 (November), 59:4, 1997.

AYDOS, E.D. O resgate do ostracismo para uma atribuição positiva de responsabilidade política, excertos de Democracia plebiscitária: utopia e simulacro de reforma política no Brasil. 1995, Ed. Da Universidade/UFRGS, 2000.

BURGAIN, M.S. Vote splitting, reelection and electoral control: a unified model. Seminário $n^{\circ}$ 12/00 do Programa de Seminários Acadêmicos da UnB (disponível na página www.unb.br/ih/eco); 2000.

BURGAIN, M.S. Vote splitting as insurance against uncertainty. Public Choice, 98:153169, 1999.

COX, G.W. $\& 3$ Katz, J.N. Why did the incumbency advantage in U.S. House elections grow? American Journal of Political Science, 1996 (May), 40:2.

DANIEL, K. \& LOTT, Jr., J.R. Term limits and electoral competitiveness: evidence from California's state legislative races. Public Choice, 1997 (March); 90:1-4.

DICK, A.R. \&3 LOTT, Jr., J.R. Reconciling voter's behavior with legislative term limits. Journal of Public Economics, 1993 (January); 50:1.

FRIEDMAN, D, $\mathcal{G}$ WITTMAN, D. Why voters vote for incumbents but against incumbency: a rational choice explanation. Journal of Publics Economics, 1995 (May); 57:1.

LAFFONT, J.-J. 8 TIROLE, J. A theory of incentives in procurement and regulation. The MIT Press, 1993.

LAU, R. $\mathcal{B}$ REDLAWSKI, D.P. Voting correctly. American Political Science Review, (September), 91:3, 1997. 
PELTZMAN, S. Towards a more general theory of regulation. Journal of Law and Economics, 19:2, 1976.

PEREIRA, C. 8 MUELLER, B. A Theory of Executive... in Brazilia Congress. Journal of Legislatives Studies, vol. 10, n. 1, Spring: 9-49, 2004.

REIS, F.W Que tal experimentar? Política Hoje, edição on line, www.politicahoje.com.br/ ideias0004.htm;. 2000.

SHAPIRO, Carl \& STIGLITZ, Joseph E. "Equilibrium Unemployment as a Worker Discipline Device". American Economic Review. Volume 74, n. 3 (June), p. 433-44, 1984. WRIGHTON, J.M. 8 SQUIRE, P. Uncontested seats and electoral competition for U.S. House of Representatives over time. The Journal of Politics, 1997 (May), 59:2, 1997. 


\section{Apêndice}

Neste apêndice, apresenta-se a dedução das equações (20) e (21) do desenvolvimento. As probabilidades para reeleições sucessivas, de acordo com as hipóteses assumidas no texto, no caso de o eleitorado não praticar a seleção por competência são as seguintes: probabilidade de reeleição pela $1^{\mathrm{a}}$ vez: $x$; probabilidade de reeleiçāo pela $2^{\mathrm{a}}$ vez: $x^{2}$; probabilidade de reeleição pela $3^{a}$ vez: $x^{3}$; e assim por diante.

$\mathrm{Em} t=0$, os políticos são eleitos pela primeira vez. Normalizandose o número de cadeiras da Casa para 1 , resulta que a senhoridade média em termos de mandatos anteriores cumpridos é igual a zero.

Na segunda eleição, $t=1$, o número de políticos reeleitos pela primeira vez é $x$, e o de eleitos pela primeira vez é $1-x$. Assim, a senhoridade média é dada pela equação seguinte:

$$
\bar{S}=1 \times x+0 \times(1-x)=x
$$

onde o um e o zero referem-se ao número de mandatos cumpridos pelos políticos eleitos nesse período.

Na segunda eleição, $t=2$, os reeleitos pela segunda vez são $x^{2}$, os reeleitos pela primeira vez são $x(1-x)$ e os eleitos pela primeira vez são $x(1-x)+(1-x)^{2}$. A senhoridade média é então dada pela seguinte expressão:

$$
\bar{S}=2 \times x^{2}+x-x^{2}=x(1+x)
$$

Repetindo-se indefinidamente essas operações, chega-se à seguinte expressāo:

$$
\bar{S}=x\left(1+x+x^{2}+x^{3}+x^{4}+\cdots\right.
$$

de onde se chega finalmente à expressão (20), considerando-se que $x \in(0,1)$ :

$$
\bar{S}=\frac{x}{1-x}
$$

As probabilidades para reeleições sucessivas, de acordo com as hipóteses assumidas no texto, no caso de o eleitorado exercitar a seleção por competência, são as seguintes: probabilidade de reeleição pela $1^{\mathrm{a}}$ vez: $x$; probabilidade de reeleição pela $2^{a}$ vez: $R x$; probabilidade de reeleição pela $3^{a}$ vez: $R^{2} x$; probabilidade de reeleição pela $4^{a}$ vez: $R^{3} x$; probabilidade de reeleição pela $5^{a}$ vez: $R^{4} x$; e assim por diante.

Em $t=0$, os políticos são eleitos pela primeira vez. Normalizando-se o número de cadeiras da Casa para I, resulta que a senhoridade média em termos de mandatos anteriores cumpridos é igual a zero. 
Na segunda eleição, $t=1$, o número de políticos reeleitos pela primeira vez é $x$, e o de eleitos pela primeira vez é $1-x$. Assim, a senhoridade média é dada pela equação seguinte:

$$
\bar{S}=1 \times x+0 \times(1-x)=x
$$

onde o um e o zero referem-se ao número de mandatos cumpridos pelos políticos eleitos nesse período.

Na segunda eleição, $t=2$, os reeleitos pela segunda vez são $R x^{2}$, os reeleitos pela primeira vez são $x(1-x)$ e os eleitos pela primeira vez são $x(1-R x)+(1-x)^{2}$. A senhoridade média é, então, dada pela seguinte expressão:

$$
\bar{S}=2 \times R x^{2}-x^{2}+x=x[(2 R-1) x+1]
$$

Repetindo-se essas operações até $t=4$, chega-se à expressão (21), que é equivalente à seguinte:

$$
\bar{S}=x^{4}\left(4 R^{6}-4 R^{3}-2 R^{2}+4 R-1\right)+x^{3}\left(3 R^{3}-3 R+1\right)+x^{2}(2 R-1)+x
$$

O expoente mais alto de $R$ no coeficiente da potência $x^{n}$ é igual à soma dos inteiros positivos de zero até $n-1$ e o coeficiente numérico dessa potência de $R$ é sempre $n$. Daí concluir-se que o primeiro termo da expressão entre parênteses da potência $x^{n}$ é o seguinte:

$$
n R^{\frac{n(n-1)}{2}}
$$

que, por inspeção dos demais coeficientes, foi usado como limitante do coeficiente da potência de $x$, conforme expressão (26). 